\title{
The Influence of C-Ions and X-rays on Human Umbilical Vein Endothelial Cells
}

\author{
Alexander Helm ${ }^{1 *}$, Ryonfa Lee ${ }^{1 \dagger}$, Marco Durante ${ }^{1,2}$ and Sylvia Ritter ${ }^{1}$ \\ ${ }^{1}$ Department of Biophysics, GSI Helmholtz Centre for Heavy lon Research, Darmstadt, Germany, ${ }^{2}$ Department of \\ Condensed Matter Physics, Technical University of Darmstadt, Darmstadt, Germany
}

OPEN ACCESS

Edited by:

John Varlotto,

University of Massachusetts

Medical Center, USA

Reviewed by:

Michael Wayne Epperly,

University of Pittsburgh Cancer

Institute, USA

Clemens Grassberger,

Harvard Medical School, USA

Eric Chi-Ching Ko,

UC Davis Comprehensive

Cancer Center, USA

*Correspondence:

Alexander Helm

a.helm@gsi.de

tPresent address:

Ryonfa Lee,

Nuffield Department of

Population Health, University of

Oxford, Oxford, UK

Specialty section:

This article was submitted to Radiation Oncology, a section of the journal Frontiers in Oncology

Received: 23 September 2015 Accepted: 04 January 2016

Published: 20 January 2016

Citation:

Helm A, Lee R, Durante M and Ritter S (2016) The Influence of

$C$-lons and $X$-rays on Human Umbilical Vein Endothelial Cells.

Front. Oncol. 6:5.

doi: 10.3389/fonc.2016.00005
Damage to the endothelium of blood vessels, which may occur during radiotherapy, is discussed as a potential precursor to the development of cardiovascular disease. We thus chose human umbilical vein endothelial cells as a model system to examine the effect of low- and high-linear energy transfer (LET) radiation. Cells were exposed to $250 \mathrm{kV}$ $\mathrm{X}$-rays or carbon ions (C-ions) with the energies of either $9.8 \mathrm{MeV} / \mathrm{u}(\mathrm{LET}=170 \mathrm{keV} / \mu \mathrm{m})$ or $91 \mathrm{MeV} / \mathrm{u}(\mathrm{LET}=28 \mathrm{keV} / \mu \mathrm{m})$. Subculture of cells was performed regularly up to 46 days ( 22 population doublings) post-irradiation. Immediately after exposure, cells were seeded for the colony forming assay. Additionally, at regular intervals, mitochondrial membrane potential (MMP) (JC-1 staining) and cellular senescence (senescenceassociated $\beta$-galactosidase staining) were assessed. Cytogenetic damage was investigated by the micronucleus assay and the high-resolution multiplex fluorescence in situ hybridization (mFISH) technique. Analysis of radiation-induced damage shortly after exposure showed that $\mathrm{C}$-ions are more effective than $\mathrm{X}$-rays with respect to cell inactivation or the induction of cytogenetic damage (micronucleus assay) as observed in other cell systems. For 9.8 and $91 \mathrm{MeV} / \mathrm{u} \mathrm{C}$-ions, relative biological effectiveness values of 2.4 and 1.5 were obtained for cell inactivation. At the subsequent time points, the number of micronucleated cells decreased to the control level. Analysis of chromosomal damage by $\mathrm{mFISH}$ technique revealed aberrations frequently involving chromosome 13 irrespective of dose or radiation quality. Disruption of the MMP was seen only a few days after exposure to X-rays or C-ions. Cellular senescence was not altered by radiation at any time point investigated. Altogether, our data indicate that shortly after exposure C-ions were more effective in damaging endothelial cells than X-rays. However, late damage to endothelial cells was not found for the applied conditions and endpoints.

Keywords: cardiovascular disease, endothelial cells, high-LET radiation, carbon ions, carbon ion therapy, chromosome 13, micronucleus formation, senescence-associated $\beta$-galactosidase

Abbreviations: CPD, cumulative population doublings; HUVEC, human umbilical vein endothelial cells; JC-1, 5,5',6,6'-tetrachloro-1,1',3,3'-tetraethylbenzimidazolyl-carbocyanine iodide; LET, linear energy transfer; mFISH, multiplex fluorescence in situ hybridization; MMP, mitochondrial membrane potential; RBE, relative biological effectiveness; SA- $\beta$-gal, senescenceassociated $\beta$-galactosidase. 


\section{INTRODUCTION}

An increased risk of cardiovascular disease (CVD), i.e., any disease involving the heart or blood vessels, such as ischemic heart disease, myocardial infarction, or hypertension, is a known consequence of radiotherapy for the treatment of certain types of cancer, such as breast cancer or Hodgkin lymphoma, where the heart is typically part of the radiation field and thus may be exposed to relatively high doses of ionizing radiation (IR) $(1,2)$. Although modern radiotherapy techniques aim to spare organs at risk such as the heart, coronary arteries may still be affected and thus a risk for cardiovascular damage remains $(3,4)$. Furthermore, there is growing evidence of an increased risk of CVD at low and moderate doses of IR stemming mainly from atomic bomb survivors and occupationally exposed groups, typically developing with a long latency (5-7). Generally, radiation-induced cell killing of endothelial cells and a subsequent induction of a pro-inflammatory response are considered as the mechanism triggering arteriosclerosis and ischemic heart disease $(6,8,9)$. The mechanisms by which low and moderate doses of IR provoke CVD are still poorly understood. However, direct damage to endothelial cells followed by an inflammatory response seems to play also a role at low doses $(6,10)$.

Radiation-induced damage to the endothelium may simply be a consequence of cell loss due to cell killing, as discussed by Little et al. (6). Yet, also radiation-induced genomic instability, oxidative stress disrupting mitochondrial function, and accelerated cellular senescence have been implicated in the pathogenesis of arteriosclerosis $(8,11-14)$. So far, most data are available on the effects of low-linear energy transfer (LET) radiation, while only few data on the impact of high-LET radiation exist, yet suggesting a higher risk (10). With an increasing use of high-LET particles such as carbon ions (C-ions) in cancer therapy or radiosurgery (15-17), an assessment of their possible cardiovascular effects is important.

To gain a deeper insight into the effects of high-LET radiation on endothelial cells, we chose human umbilical vein endothelial cells (HUVEC) as a model system. HUVEC have been already used to study the radiation response to both low- and high-LET radiation investigating, e.g., cell survival, apoptosis, gene expression, or angiogenesis [e.g., Ref. (18-20)]. We exposed cells to C-ions with two different energies relevant for cancer therapy, i.e., 9.8 and $91 \mathrm{MeV} / \mathrm{u}$ corresponding to LET values of 170 and $28 \mathrm{keV} / \mu \mathrm{m}$. For comparison, X-ray experiments were performed. The focus was set on doses $\leq 1.5 \mathrm{~Gy}$. We investigated clonogenic cell survival, apoptosis, and cytogenetic damage expressed as micronuclei formation or chromosomal aberrations, premature senescence, and the integrity of the mitochondrial membrane potential (MMP). Measurements were performed up to 46 days post-irradiation.

\section{MATERIALS AND METHODS}

\section{Cell Culture}

Human umbilical vein endothelial cells were purchased from PromoCell (Heidelberg, Germany) and cultured according to the manufacturer's protocol in medium optimized for the cultivation of primary endothelial cells from large blood vessels. Briefly, cells were maintained in basal Endothelial Cell Growth Medium supplemented with Endothelial Cell Growth Kit components. The final supplement concentrations in the medium were $2 \%$ fetal calf serum, $0.1 \mathrm{ng} / \mathrm{ml}$ epidermal growth factor, $1 \mu \mathrm{g} / \mathrm{ml}$ hydrocortisone, $1 \mathrm{ng} / \mathrm{ml}$ basic fibroblast growth factor, and $0.4 \%$ endothelial cell growth supplement. Cells were passaged every $4-5$ days upon reaching $\sim 80 \%$ confluency. For cell detachment, a mixture of $0.05 \%$ trypsin and $0.02 \%$ EDTA was used and neutralized with trypsin neutralizing solution containing $0.05 \%$ trypsin inhibitor in $0.1 \% \mathrm{BSA}$ and plated at a density of $6.6 \times 10^{3} \mathrm{cells} / \mathrm{cm}^{2}$ unless otherwise stated. Medium was changed for every 2-3 days, and the cumulative population doubling (CPD) was determined. All cell culture products were purchased from PromoCell.

\section{Irradiation}

Sub-confluent cultures with a CPD level of about 6 (culture age: about 11 days) were exposed to X-rays or $\mathrm{C}$-ions with an initial energy of either 11.4 or $100 \mathrm{MeV} / \mathrm{u}$ at GSI Helmholtz Centre for Heavy Ion Research (Darmstadt, Germany). For the exposure to X-rays or high energy C-ions, cells were seeded into $25 \mathrm{~cm}^{2}$ culture flasks, whereas for the exposure to low energy C-ions, cells were plated into $35 \mathrm{~mm}$ Petri dishes.

$\mathrm{X}$-ray irradiation was performed at a Seifert (Germany) $\mathrm{X}$-ray machine operated at $250 \mathrm{kV}$ and $16 \mathrm{~mA}$ with a $1 \mathrm{~mm}$ $\mathrm{Al}+1 \mathrm{~mm} \mathrm{Cu}$ filtering. The dose rate was about $1.5 \mathrm{~Gy} / \mathrm{min}$. Exposure to $11.4 \mathrm{MeV} / \mathrm{u} \mathrm{C}$-ions was done at the linear accelerator UNILAC, as described in detail elsewhere $(21,22)$. At sample position, the energy was $9.8 \mathrm{MeV} / \mathrm{u}$ corresponding to an LET of $170 \mathrm{keV} / \mu \mathrm{m}$. Irradiation with $100 \mathrm{MeV} / \mathrm{u}$ C-ions was performed at the heavy ion synchrotron SIS with the raster scanning technique (23). The resulting energy on target was $91 \mathrm{MeV} / \mathrm{u}$ with an LET of $28 \mathrm{keV} / \mu \mathrm{m}$. For C-ions, the irradiation time was in the range of $0.5-2$ min depending on dose and accelerator conditions. All exposures were done at room temperature, and control samples were sham irradiated.

For longer follow-up studies (up to 46 days post-irradiation corresponding to 22 population doublings), we limited the analyses to doses at an isosurvival level of about 50 and $20 \%$, respectively. Cell survival of $50 \%$ was expected for $0.75 \mathrm{~Gy} \mathrm{X}$-rays, $0.35 \mathrm{~Gy} 91 \mathrm{MeV} / \mathrm{u}$ C-ions, and $0.25 \mathrm{~Gy} 9.8 \mathrm{MeV} / \mathrm{u}$ C-ions, while a survival rate of $20 \%$ was estimated for $1.5,0.75$, and $0.5 \mathrm{~Gy}$, respectively. Further details on particle fluences and the number of particle traversals per nucleus are given in Table S1 in Supplementary Material.

\section{Clonogenic Cell Survival}

Cell survival was measured using the standard colony forming assay (24). In brief, directly after exposure cells were trypsinized, counted, and plated in triplicate into 25 or $75 \mathrm{~cm}^{2}$ tissue culture flasks. The number of cells seeded was estimated to result in a statistically significant formation of at least 100 colonies. After 12 days of incubation, cells were fixed and stained. Cell clusters consisting of at least 50 cells were counted as a colony. 


\section{Micronuclei}

To assess the cytogenetic damage $24 \mathrm{~h}$ after radiation exposure, the micronucleus assay was applied as described in Fenech (25) with minor modifications. Briefly, cells were incubated for $4 \mathrm{~h}$ following irradiation and subsequently treated with $0.75 \mu \mathrm{g} / \mathrm{ml}$ cytochalasin-B for $20 \mathrm{~h}$. Cells were then washed in PBS, fixed in $8 \%$ formaldehyde for $5 \mathrm{~min}$, and stained with DAPI $(0.2 \mu \mathrm{g} / \mathrm{ml})$ for $15 \mathrm{~min}$ at room temperature. At least 1000 cells were scored, and the number of binucleated cells containing micronuclei was determined. For follow-up studies, i.e., $>24$ h, cells were regularly subcultured and at selected time points the spontaneously occurring frequency of cells carrying micronuclei was analyzed by scoring 1000 cells per dose and time point.

\section{Apoptosis}

For analysis at the early time point, cells were fixed in $8 \%$ formaldehyde and stained with DAPI as described for the micronuclei samples. Additionally, cells were subcultered and at consecutive time points $5 \times 10^{4}$ cells were seeded in $35 \mathrm{~mm}$ tissue culture dishes and incubated for 2 more days until fixation and staining. At least 1000 cells were scored per dose and time point. Apoptotic cells were identified under a fluorescence microscope (400× magnification) by the typical morphological changes of the cell nucleus, such as chromatin condensation or fragmentation $(26,27)$.

\section{Senescence-Associated $\beta$-Galactosidase}

Analysis of cellular senescence-associated $\beta$-galactosidase activity (SA- $\beta$-gal) was performed using the Senescence Cell Staining kit (Sigma-Aldrich, Germany) according to the manufacturer's protocol. At several time points after radiation exposure (2 up to 44 days), cells were seeded at a density of $5 \times 10^{4}$ in $35 \mathrm{~mm}$ tissue culture dishes. Two days later, cells were fixed and staining. At least 2000 cells were scored by light microscopy $(400 \times$ magnification), and the fraction of cells exhibiting a blue stain, i.e., SA- $\beta$-gal activity, was determined.

\section{Mitochondrial Membrane Potential}

To assess the influence of radiation exposure on the MMP (also referred to as $\Delta \Psi_{\mathrm{M}}$ ), the cationic, lipophilic dye $5,5^{\prime}, 6,6^{\prime}$-tetrachloro-1,1',3,3'-tetraethylbenzimidazolyl-carbocyanine iodide (JC-1) was applied. The dye shifts its fluorescence signal from $525 \mathrm{~nm}$ (green) to $595 \mathrm{~nm}$ (red) due to a dimerization in the presence of protons thus indicating a functional MMP. For MMP analyses, samples were collected 12,24 , and $48 \mathrm{~h}$ after exposure. Measurements at later time points were performed using $~ 80 \%$ confluent cultures. Analysis of the MMP was performed as described previously (28) with modifications. Briefly, cells were harvested and incubated for $10 \mathrm{~min}$ in medium containing JC-1 $(5 \mu \mathrm{g} / \mathrm{ml})$ at $37^{\circ} \mathrm{C}$. Thereafter, cells were washed twice with PBS analyzed by flow cytometry using a Pas III Particle Analysing System and the software FloMax (both from Partec, Germany). The fraction of predominantly red cells, i.e., cells mainly containing mitochondria with an intact MMP, was determined in at least $1 \times 10^{4}$ cells of each sample. As a positive control, cells were treated with $2 \mathrm{mM}$ 2,4-dinitrophenol 10 min before JC-1 staining, resulting in $\sim 5 \%$ of cells with a red fluorescent signal.

\section{Chromosome Analysis}

Chromosome aberrations were analyzed in control cultures at CPD $13 \pm 2$ and in the progeny of irradiated cells at CPD $22 \pm 2$. For cytogenetic analyses, cells were seeded into $75 \mathrm{~cm}^{2}$ flasks and cultured for 2 days. Then, colcemid $(0.1 \mu \mathrm{g} / \mathrm{ml})$ was added for $3 \mathrm{~h}$ to accumulate metaphase cells. Chromosome spreads were prepared according to the standard procedures, e.g., cells were trypsinized, treated with hypotonic solution, fixed, and dropped on wet slides. Slides were stained using multiplex fluorescence in situ hybridization (mFISH). For mFISH analysis, slides were hybridized with the 24XCyte mFISH probe kit from MetaSystems (Altlussheim, Germany) following the instructions of the manufacturer. Chromosome spreads were examined using an Olympus BX61 microscope (Olympus, Tokyo, Japan) equipped with six filter sets specific for the applied fluorochromes. Images of the metaphases were captured (100× objective) with a charged coupled device camera, and karyotyping was performed using the ISIS/mFISH software. Both, structural and numerical aberrations were recorded in at least 100 metaphases per dose and time point. Structural aberrations were classified following the mPAINT system, as described in detail elsewhere (29). In the present study, breaks and simple exchanges were detected. Breaks were referred to as terminal deletions, when the centric and acentric part of the same chromosome were present within the cell. Terminal deletions involved either both chromatids at the same location (chromosome-type breaks, csb) or only one chromatid (chromatid-type break, ctb). Additionally, lone truncated chromosomes (T) were found, i.e., the acentric part of chromosome was not visible. Simple exchanges include translocations (complete, incomplete, and one-way forma) and dicentrics.

\section{Statistics}

When applicable, data were expressed as the mean value \pm SEM or SD as indicated. For data stemming from one experiment only, Poisson statistics were applied to calculate the error bars as indicated, and statistical analysis was performed using a Fisher's exact test as indicated. Survival data have been normalized by evaluating the plating efficiency not considering control data ( $0 \mathrm{~Gy})$ only, but rather by performing a fit of the form $(\alpha \times d+o)$ to the experimental data, where $o$ is an offset term, which reflects the plating efficiency, determined from all data points. This procedure is more precise, as all measured data are subject to the same plating efficiency and consequently all data points can be exploited to derive this quantity. Deviations for $0 \mathrm{~Gy}$ to full survival arises, as also control measurements are affected by uncertainty. Based on the $\alpha$-values derived from the linear fitting, a Student's $t$-test was used for statistical analysis. Curve fitting of the micronuclei formation $24 \mathrm{~h}$ after exposure was performed according to

$$
Y=p_{1} D \times e^{-p_{2} D}
$$

where $Y$ is the yield of micronuclei, $D$ the dose, and $p_{1}$ and $p_{2}$ fitting parameters. Statistical analysis was performed based 
on the parameters derived from the fitting using a Student's $t$-test. Generally, differences were considered significant if the $p$-value $\leq 0.01$.

\section{RESULTS}

\section{Radiation Affects Clonogenic Cell Survival and Micronuclei Formation in a Dose- and LET-Dependent Manner $24 \mathrm{~h}$ after Exposure}

To examine the putative radiation effect directly after exposure, a clonogenic cell survival assay was performed (Figure 1). For the three radiation types investigated cell survival decreased with dose and showed a clear LET dependence, i.e., 9.8 MeV/u $\mathrm{C}$-ions with $\mathrm{LET}=170 \mathrm{keV} / \mu \mathrm{m}$ were most effective, followed by $91 \mathrm{MeV} / \mathrm{u} \mathrm{C}$-ions with $\mathrm{LET}=28 \mathrm{keV} / \mu \mathrm{m}$ and $\mathrm{X}$-rays with $2 \mathrm{keV} / \mu \mathrm{m}$. As all survival curves are linear, the relative biological effectiveness (RBE) does not depend on survival level, resulting in values of 2.4 and 1.5 for 9.8 and $91 \mathrm{MeV} / \mathrm{u}$ $\mathrm{C}$-ions, respectively. Next, we measured cytogenetic damage in cells undergoing first division after exposure $(24 \mathrm{~h}$ after exposure, cytochalasin-B treatment). The analysis showed an LET-dependent formation of micronuclei in binucleated cells (Figure 2). Within the limited dose range examined a saturation in the yield of cells carrying micronuclei was observed for $>0.5$ Gy 9.8 MeV/u C-ions (Figure 2) and >2 Gy X-rays. Thus, the damage induced by IR in first division cells clearly depends on the radiation quality and dose. Apoptosis was assessed $48 \mathrm{~h}$ after radiation exposure by investigation of morphological criteria of the cell nuclei. A slightly yet insignificantly increased fraction of apoptotic cells was observed in the irradiated samples independent of dose or radiation quality (Figure 3).

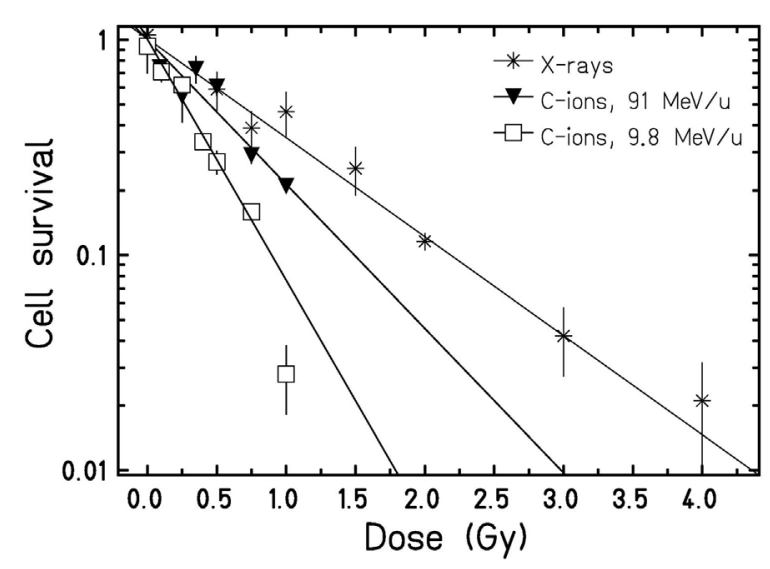

FIGURE 1 | Clonogenic cell survival of HUVEC. Cells were plated immediately after exposure to $\mathrm{X}$-rays or $\mathrm{C}$-ions. Data points represent the mean $X \pm S D$ from replicates stemming from one (C-ions) or three ( $X$-rays) experiments. Curves were fitted by a linear function. Based on the $\alpha$-values, clonogenic cell survival was found significantly ( $p<0.01$, Student's $t$-test) different for the three radiation types.

\section{Radiation-Induced Damage Is Transient Rather Than Persistent in Cells Cultured up to 46 Days Following Exposure}

For investigation of putative late effects of IR, we cultured both exposed cells and sham-irradiated cells up to 46 days corresponding to 22 population doublings post-irradiation (Figure S1 in Supplementary Material). Generally, radiation exposure did not severely alter the population growth compared to the control. Only in one case, i.e., after exposure to $1.5 \mathrm{~Gy} \mathrm{X}$-rays, a slightly lower CPD was found toward the end of the culture time.

Next, we determined the amount of cells harboring micronuclei after an extended culture time (Figure 4). To allow for a better comparison, we plotted the mean value $( \pm \mathrm{SD})$ of all controls over time instead of single data points. As shown in Figure 4, in all irradiated samples, the fraction of HUVEC containing micronuclei was significantly increased 2 days after exposure. For C-ions, the increase was dose dependent. Generally, at the following time points, only small differences between irradiated and sham-irradiated control cultures were found. Yet, exposure to the high doses ( 0.5 and $0.75 \mathrm{~Gy}$ ) low and high energy C-ions resulted in an increased fraction of cells containing micronuclei when comparing to the respective controls (not displayed) 21 and 20 days post-irradiation, respectively. These increases are above the range of the mean value of pooled controls from all experiments and its upper SD, as indicated in the graph (Figure 4). Subsequent investigation time points did not reveal significant dose effects compared to the controls. Thus, analysis of the formation of micronuclei provided no evidence for a radiation-induced chromosomal damage in the progeny of irradiated cells.

Furthermore, we investigated radiation-induced apoptosis in the descendants of irradiated cells. The morphological analysis of

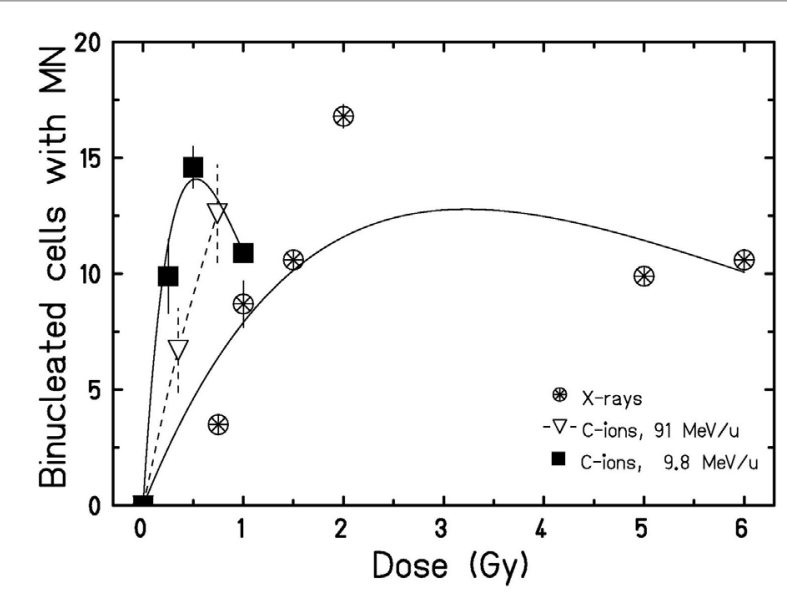

FIGURE 2 | Micronuclei formation $24 \mathrm{~h}$ after exposure. Following irradiation, cells were incubated with cytochalasin-B, and the amount of binucleated cells containing micronuclei was determined. Data points represent the mean $X_{ \pm}$SEM (for data points with $n=2$ ) or error was calculated according to Poisson statistics for data points stemming from one experiment. Curves for X-rays and 9.8 MeV/u C-ions were fitted as described. For $91 \mathrm{MeV} / \mathrm{u} \mathrm{C}$-ions, lines are drawn to guide the eye. Statistical analysis using a Student's $t$-test revealed significant differences for $9.8 \mathrm{MeV} / \mathrm{u}$ C-ions when compared to X-rays $(p<0.01)$. 

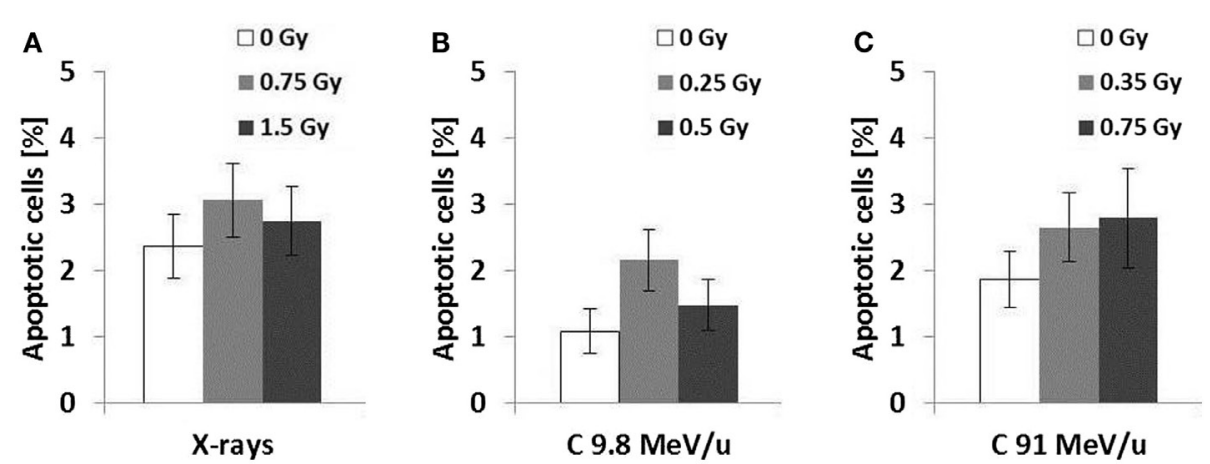

FIGURE 3 | Apoptosis $48 \mathrm{~h}$ after exposure. Cells were fixed $48 \mathrm{~h}$ following radiation exposure to X-rays (A), $9.8 \mathrm{MeV} / \mathrm{u}$ C-ions (B), and $91 \mathrm{MeV} / \mathrm{u} \mathrm{C}$-ions (C). The fraction of apoptotic cells was determined according to morphological criteria of the nucleus. Error was calculated according to Poisson statistics. Fisher's exact test revealed no significant differences between all samples $(n=1, p>0.01)$.

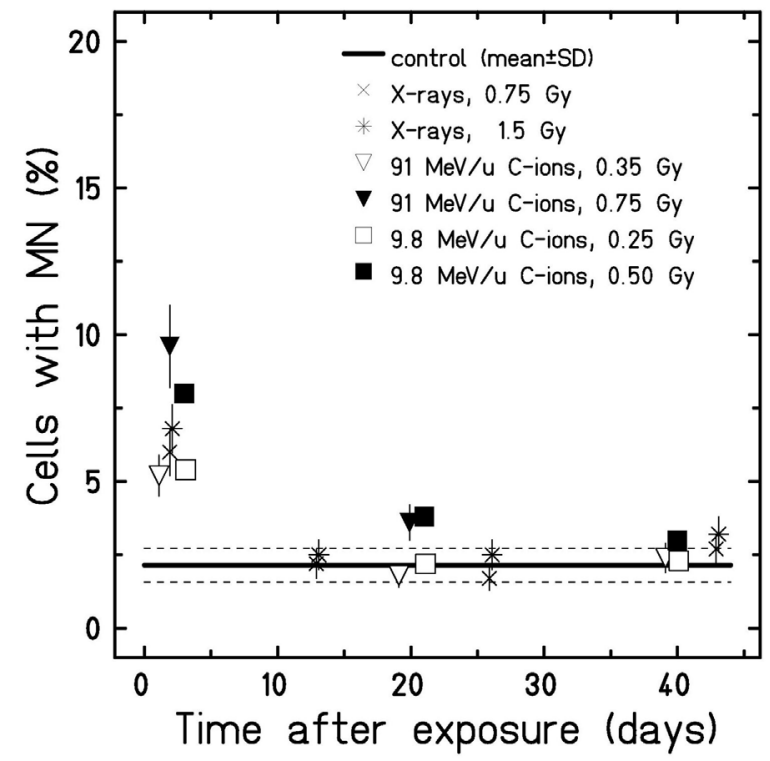

FIGURE 4 | Micronuclei formation in cells after extended culture time. Cells were fixed at several time points after exposure (w/o cytochalasin-B), and all cells harboring micronuclei were scored. The error was calculated according to Poisson statistics, and a Fisher's exact test was performed $(n=1)$. Only 2 days after exposure, micronuclei formation was found significantly higher compared to the control (mean \pm SD). Note that for better visualization, the samples 2 days after exposure to the different radiation types were plotted separated from each other despite stemming from the same time point.

the cell nuclei showed no differences in the fraction of apoptotic cells in irradiated samples compared to the respective controls (data not shown).

Additionally, the putative damage on the MMP was studied by applying the proton-sensitive dye JC-1. In control cultures $(n=4)$, the proportion of cells with an intact MMP (mainly redfluorescing cells) amounted to $79 \pm 8.4 \%$ (mean $\pm \mathrm{SD}$ ) over the whole time interval investigated (data not shown). After exposure to X-rays or C-ions, we found a slight decrease in cells with an intact MMP between 3 and 8 days post-irradiation, partly falling below the value of the lower SD (i.e., about 71\%) down to $61 \%$ (for 1.5 Gy X-rays and $0.35 \mathrm{~Gy} \mathrm{C}$-ions $91 \mathrm{MeV} / \mathrm{u}$, data not shown). To elucidate whether higher doses are required to profoundly impair mitochondrial function in HUVEC cultures within this period of time, we exposed cells to $1.5,4$, and 10 Gy X-rays and analyzed the MMP daily until 10 days after exposure (Figure S2 in Supplementary Material). We found that 2 days after exposure for all three doses applied, the amount of cells exhibiting mainly red fluorescence was lower compared to the respective control and the lower SD of all controls. Three days after irradiation with $1.5 \mathrm{~Gy} \mathrm{X}$-rays, the fraction of cells containing mitochondria with mostly intact MMP rose and reached the control level by day 5 . For cells exposed to 4 Gy X-rays, recovery started at day 6 and the control value was reached by day 7 , whereas the exposure to 10 Gy resulted in a persistently decreased level of cells with an intact MMP over the period investigated. Hence, the dose dependence was expressed rather in the recovery time than in the fraction of cells with intact MMP.

Furthermore, the expression of SA- $\beta$-gal was investigated in the progeny of irradiated and non-irradiated HUVEC to assess whether the radiation exposure induced premature senescence. Generally, the fraction of SA- $\beta$-gal positive cells raised with an increasing CPD. The proportion was comparable in irradiated samples and the respective controls. Only in one sample, i.e., 6 days after exposure to $0.5 \mathrm{~Gy} \mathrm{C}$-ions $9.8 \mathrm{MeV} / \mathrm{u}$, an increased fraction of SA- $\beta$-gal positive cells was found and thus may be considered false positive (Figure S3 in Supplementary Material). Altogether, these data indicate that within the dose range investigated neither $\mathrm{X}$-ray nor $\mathrm{C}$-ion exposure induces a premature cellular senescence of HUVEC cultures.

\section{Analysis of Chromosomal Aberrations by the mFISH Technique Revealed Specific Alterations in the Progeny of Non- Irradiated and Irradiated HUVEC \\ Cultures}

To verify the observation that the progeny of non-irradiated and irradiated cells do not express an elevated level of cytogenetic 


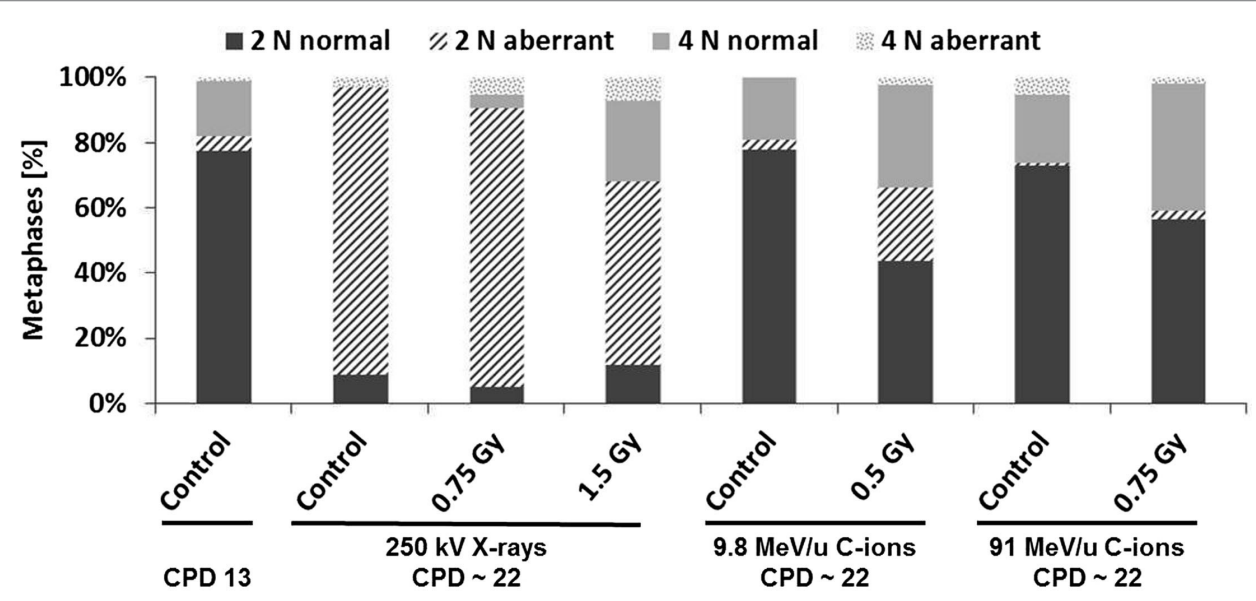

FIGURE 5 | Analysis of structural chromosome aberrations in HUVEC cultures (non-irradiated and irradiated) by means of the mFISH technique. The fractions of normal and aberrant diploid/hypodiploid cells (referred to as $\sim 2 \mathrm{~N}$ ) and tetraploid/hypotetraploid cells (referred to as $\sim 4 \mathrm{~N}$ ) are given $(n=1$ ). The terms hypodiploidy or tetradiploidy indicate the loss of one or two chromosomes. Cells were analyzed in controls at a CPD level of $13 \pm 2$ and about 9 population doublings after exposure (CPD 22).

damage (Figure 4), we measured chromosome aberrations in all cultures about 9 doublings post-irradiation corresponding to a CPD level of $\sim 22$. Additionally, the baseline level of aberrations was determined (CPD level $\sim 13$ ). The analyses were performed by means of the high-resolution mFISH technique. As shown in Figure 5, in non-irradiated HUVEC cultures at CPD 13 most cells had a normal $(2 \mathrm{~N})$ karyotype, occasionally the loss of one chromosome was observed. Overall, about $80 \%$ of the cells were diploid or hypodiploid. Notably, also tetraploid cells $(4 \mathrm{~N})$ and a few cells with a hypotetraploid karyotype were registered (in total $20 \%$ of the population). Structural aberrations (mainly breaks and translocations) were detected in $~ 5 \%$ of cells analyzed. With increasing $\mathrm{CPD}$, only small changes occurred in two control cultures (C-ion studies), but chromosome 13 appeared to be nonrandomly involved. Either it was truncated or one copy was lost. In one control culture (X-ray study), the proportion of cells with a $\sim 2 \mathrm{~N}$ karyotype was much higher at $\mathrm{CPD} \sim 22$, i.e., amounted to $97 \%$. Notably, also the number of cells with structural aberrations was highly elevated, i.e., 88/97 2N cells and 3/3 4N cells were aberrant. In all affected cells, the same aberration, a large truncation of the q-arm of chromosome 13, was observed indicating a clonal origin.

Chromosome analysis in cells at CPD $\sim 22$ (Figure 5) consistently showed that the fraction of $\sim 4 \mathrm{~N}$ cells was generally higher in the progeny of irradiated cells than in the respective controls culture. Structural aberrations were found in all cultures and were generally translocations (sporadic or clonal) or truncated chromosomes. As observed in the control cultures chromosome 13 was non-randomly involved in aberrations. Likewise, the loss of one or two chromosomes was registered. Again, chromosome 13 was over-represented (Figure 6). A summary of the data is shown in Table S2 in Supplementary Material.

Altogether, these data show that in HUVEC chromosome 13 is inherently unstable. Frequently, cells with a lost or truncated chromosome were observed. Based on the number of
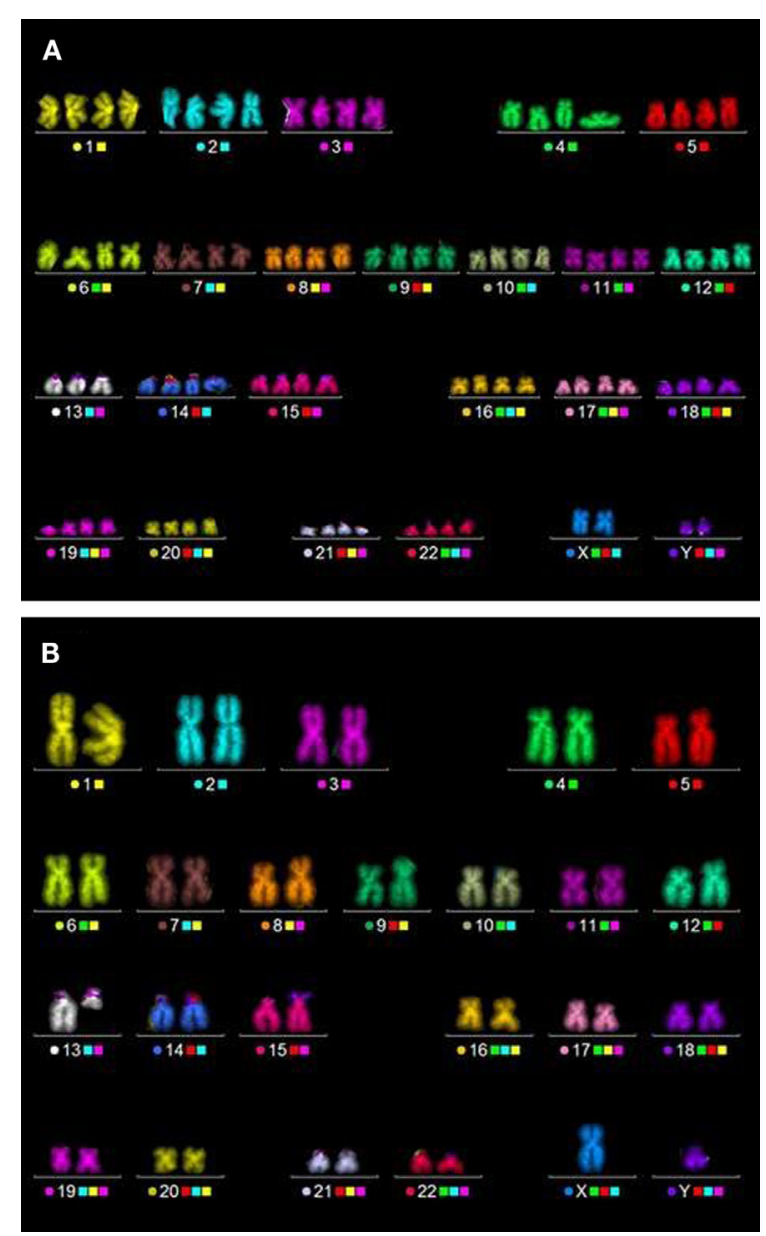

FIGURE 6 | Typical aberrations detected in HUVEC by means of the mFISH technique. (A) Hypotetraploid cell, one copy of chromosome 13 is lost. (B) Diploid cell, one chromosome is truncated (here: non-irradiated cells, CPD 22). 
cells affected (i.e., the clone sizes), the loss or the deletion of a large part of the q-arm of chromosome 13 results in a survival advantage. As these changes are clonal they remain undetected by micronucleus analysis.

\section{DISCUSSION}

Epidemiological data demonstrate an increased risk of CVD when the heart and its adjacent blood vessels are exposed to relatively high doses of low-LET radiation as a consequence of radiotherapy, e.g., breast cancer or Hodgkin lymphoma ( 1 , $2,30)$. An increased risk of CVD at low or moderate doses of IR is indicated by epidemiological data stemming mainly from atomic bomb survivors or occupationally exposed groups ( 7 , 31). However, the mechanisms leading to CVD after exposure to IR remain to be elucidated. The available data point at damage to the endothelial cells as the initial event in pathogenesis (31). Hence, we chose HUVEC as a model system. This system bears two advantages. First, the umbilical cord provides a cost-effective source of endothelial cells. Second, in several studies, the effect of low LET on HUVEC has already been examined [e.g., Ref. (32, 33)]. Since data on high-LET C-ions are scarce but of great interest owing to the increased use of $\mathrm{C}$-ions in modern radiotherapy (15-17), we analyzed the response of HUVEC after exposure to $\mathrm{C}$-ions with energies relevant for radiotherapy (see Table S1 in Supplementary Material).

\section{Radiation Induces a Dose- and LET- Dependent Damage in HUVEC $24 \mathrm{~h}$ Following Exposure}

In HUVEC, radiation-induced damage in terms of clonogenic survival was found to depend on both dose and LET (Figure 1). For $91 \mathrm{MeV} / \mathrm{u} \mathrm{C}$-ions, an RBE value of 1.5 was obtained, whereas 9.8 MeV/u C-ions resulted in an RBE of 2.4. This is in line with the data reported for other cell lines [e.g., Ref. $(34,35)]$. Cell survival of HUVEC after exposure to low-LET radiation was already measured by others $(36,37)$, but the radiosensitivity of cells used in the present study was much higher. For example, in the present study, a surviving fraction of $10 \%$ was reached after exposure to 2 Gy X-rays (Figure 1), whereas 4 and 5 Gy were needed for the same effect in the studies of Manti et al. and Hei et al., respectively. Furthermore, the survival data published by both authors show a shoulder, typically observed after exposure to low-LET photons. By contrast, our X-ray data display no shoulder. Lack of a shoulder points to a higher radiosensitivity and might be caused, for example, by a reduced DNA repair capacity as reported for Ku80deficient cell lines [e.g., Ref. (34)]. Since HUVEC originate from apparently healthy donors, it is unlikely that the observed difference in the shape of the survival curves is attributable to compromised DNA repair. Yet, one possible explanation is a difference in the cell culture condition. In the present study, a specialized medium for primary endothelial cells was used with $2 \%$ serum, while Hei et al. cultured HUVEC in medium with $20 \%$ serum. Manti et al. studied also the response of HUVEC after exposure to C-ions with different LET values (13 and $100 \mathrm{keV} / \mu \mathrm{m}$ ) and reported a clear dose and LET dependence as found in our study, too. For C-ions with a high LET $(100 \mathrm{keV} / \mu \mathrm{m})$, Manti et al. did not find a shoulder either.

As observed for cell survival, C-ions were more effective than X-rays with respect to the formation of micronuclei in binucleated cells (Figure 2). Analogously, 9.8 MeV/u C-ions were more effective than $91 \mathrm{MeV} / \mathrm{u} \mathrm{C}$-ions due to the higher LET. The fraction generally increased with dose, however, after X-ray irradiation, a saturation was found for doses $>2$ Gy (data not shown). The available data indicate that for $9.8 \mathrm{MeV} / \mathrm{u} \mathrm{C}$-ions, the saturation occurred at a much lower dose (>0.5 Gy). Yet, for firm conclusions, measurements have to be performed over a wider range of doses. A dose-dependent increase in the rate of micronuclei in various rat, bovine, or human endothelial cell cultures $(38,39)$, and a saturation effect for doses around 2 Gy X-rays (38) has been reported by others and is in line with our findings (Figure 2). Since we screened for micronuclei in binucleated cells, the saturation may be correlated with a hampered cell division capacity for higher doses. Furthermore, cytochalasin-B is cytotoxic, thus an increased rate of apoptosis may compete with the formation of binucleated cells, additionally leading to an underestimation of the damage induced by IR.

In contrast to the damage induced as reduced clonogenic survival or micronuclei formation, apoptosis was found to be only slightly higher after exposure, independent from dose or applied radiation quality (Figure 3 ). A small increase in the fraction of apoptotic cells for HUVEC after exposure to low doses of X-rays is in line with literature (20).

Taken together, radiation does induce damage up to $24 \mathrm{~h}$ following exposure that depends both on dose and the LET value. Such damage to endothelial cells may be considered the initial event in the pathogenesis of CVD (31). However, CVD has a long latency period. Therefore, we investigated whether genetic damage persists in cultures and whether other cellular processes implicated in the pathogenesis of CVD were affected up to 46 days after exposure corresponding to 22 population doublings.

\section{Radiation-Induced Damage Does Not Persist}

Genomic instability, disrupted mitochondrial function, and accelerated replicative cellular senescence are implicated in pathogenesis of arteriosclerosis $(8,11-14)$. To address this topic, we assessed micronuclei formation, occurrence of chromosomal aberrations, apoptosis, and changes in the MMP as well as the expression of SA- $\beta$-gal in HUVEC cultured up to 22 population doublings after exposure (Figure S1 in Supplementary Material). For follow-up investigations, we focused on low doses up to 0.75 and 1.5 Gy for $\mathrm{C}$-ions and $\mathrm{X}$-rays, respectively, comparable to each other by isosurvival levels.

A dose-dependent effect on the number of cells with micronuclei was still visible at $48 \mathrm{~h}$ following exposure (Figure 4). At the later time points, the fraction of cells with micronuclei was similar in irradiated and control cultures indicating that the genomic stability of the cells was not affected by IR. Genomic instability expressed as micronuclei formation is a known consequence of exposure to IR (40). Yet, to the best 
of our knowledge, no other data sets for endothelial cells cultured for a prolonged time post-irradiation are available for comparison.

Premature senescence is considered as a key cellular stress response resulting, e.g., from DNA damage (41-43). Likewise, data indicate that premature senescence may contribute to the pathogenesis of arteriosclerosis $(44,45)$. Along this line, we examined the activation of SA- $\beta$-gal, a marker of cellular senescence (46) in the progeny of irradiated HUVEC.

Generally, no radiation-induced alterations were found over the time course investigated when compared to controls (Figure S3 in Supplementary Material). Only in one sample (0.5 Gy of $9.8 \mathrm{MeV} / \mathrm{u}$ C-ions), an elevated number of SA- $\beta$ gal positive cells was found 6 days after exposure that did not persist. Published data for endothelial cells are in contrast to our results. For example, Grossi et al. (47) registered a higher number of SA- $\beta$-gal expressing HUVEC several passages after exposure to $1.75 \mathrm{~Gy} \mathrm{X}$-rays or $0.5 \mathrm{~Gy} \mathrm{C}$-ions $(13 \mathrm{keV} / \mu \mathrm{m})$, i.e., doses comparable to the one in the current study. An increased number of endothelial cells, including HUVEC expressing SA- $\beta$-gal, was also observed after exposure to higher doses (2-10 Gy) of X-rays (48-50). Reasons for this different response are still unknown. Yet, studies over an extended culture time consistently showed an increase in the number of SA- $\beta$-gal positive endothelial cells with cell age $(47,51,52)$. Our data support this finding.

There is evidence that radiation-induced oxidative stress and hampered mitochondrial function (53) play a role in endothelial dysfunction and CVDs $(31,54,55)$. For example, in heart tissue, an impairment of mitochondrial proteins related to oxidative phosphorylation (e.g., complex I and III) was demonstrated following exposure to $\leq 2$ Gy X-rays (56). Therefore, we examined the MMP, a key parameter of mitochondrial function. The dye JC-1, whose red fluorescence is directly correlated with the integrity of the MMP (57), was applied (data not shown). We found a slight decrease in the amount of cells containing mainly mitochondria with an intact MMP shortly after exposure (i.e., up to 8 days) independent of the radiation type and dose. Yet, by applying higher doses of X-rays $(1.5,4$, and $10 \mathrm{~Gy})$, we recorded an impairment of mitochondrial function in HUVEC that increased with dose (Figure S2 in Supplementary Material). Likewise, a decrease of the MMP following staining with JC- 1 or other fluorescent dyes after high doses of X-rays ( $\leq 10 \mathrm{~Gy}$ ) was reported for other cell lines (58-60).

A stress-triggered decrease of the MMP may be related to the onset of apoptosis via cytochrome $c$ release and subsequent signaling pathways (61). In this context, our findings collectively provide no evidence for a delayed radiation-induced apoptosis in HUVEC.

Interestingly, the number of structural and numerical chromosomal aberrations increased with culture time in the progeny of unirradiated and irradiated cells. Consistently, chromosome 13 was involved. While, to the best of our knowledge, truncation of chromosome 13 in HUVEC has not yet been described, its loss has already been reported by others
$(51,62,63)$ and was accompanied by a growth advantage, i.e., leading to clonal expansion. Our data show that not only the complete deletion of chromosome 13 but also a deletion of a large part of the q-arm of chromosome 13 confers a growth advantage to the affected cells. Noteworthy, the q-arm of chromosome 13 harbors the $R b$ gene, encoding for the $\mathrm{Rb}$ protein, a well-known tumor suppressor and regulator of the cell cycle (64) that may account for an enhanced replication. As the number of cells with cytogenetic changes increased with time in irradiated cultures and the respective controls in a similar way, it is reasonable to assume that these cytogenetic changes are a feature of aging HUVEC that is barely affected by IR within the dose range examined (0.5-1.5 Gy). Moreover, our data revealed considerable inter-experimental differences in the number and types of aberrations in HUVEC cultures at CPD level 22 (see Figure 4; Table S2 in Supplementary Material). Pronounced inter-experimental differences in the aberration yield were also reported for other cell types, e.g., human foreskin fibroblasts and skin fibroblasts, subcultured up to CPD level 50 (41). Reasons underlying this phenomenon remain to be elucidated.

Taken together, our data point to a radiosensitivity for HUVEC directly after exposure to radiation, i.e., mainly by cell killing and even low or moderate doses as used in this study result in a reduced cellular survival. This is important if endothelial cell damage is taken into account as the initial step in the pathogenesis of arteriosclerosis (31). It was hypothesized that endothelial cell damage may trigger pro-inflammatory signals, which finally results in the enhanced formation of arteriosclerotic lesions [e.g., Ref. (6, 31)]. Yet, the link between radiation-induced damage and proinflammatory signaling remains poorly understood and requires further investigation. Since we found C-ions LET dependently more effective (RBE of 1.5 and 2.4 for 91 and $9.8 \mathrm{MeV} / \mathrm{u}$ C-ions, respectively) than $\mathrm{X}$-rays, our results demonstrate the need of further studies in order to better estimate a putative risk of highLET radiation.

\section{AUTHOR CONTRIBUTIONS}

$\mathrm{AH}, \mathrm{RL}, \mathrm{MD}$, and SR have substantially contributed to the conception and design of the work, as well as the acquisition, analysis, and interpretation of the data.

\section{ACKNOWLEDGMENTS}

The authors acknowledge P. Hessel and D. Szypkowski for skillful assistance as well as M. Scholz, T. Friedrich, W. Becher, and G. Lenz for planning and realizing the particle exposure of cells.

\section{SUPPLEMENTARY MATERIAL}

The Supplementary Material for this article can be found online at http://journal.frontiersin.org/article/10.3389/ fonc. 2016.00005 


\section{REFERENCES}

1. Darby SC, Ewertz M, McGale P, Bennet AM, Blom-Goldman U, Brønnum D, et al. Risk of ischemic heart disease in women after radiotherapy for breast cancer. N Engl J Med (2013) 368:987-98. doi:10.1056/NEJMoa1209825

2. Aleman BMP, Moser EC, Nuver J, Suter TM, Maraldo MV, Specht L, et al. Cardiovascular disease after cancer therapy. EJC Suppl (2014) 12:18-28. doi:10.1016/j.ejcsup.2014.03.002

3. Hodgson DC. Late effects in the era of modern therapy for Hodgkin lymphoma. Hematology Am Soc Hematol Educ Program (2011) 2011:323-9. doi:10.1182/asheducation-2011.1.323

4. Lemanski C, Thariat J, Ampil FL, Bose S, Vock J, Davis R, et al. Image-guided radiotherapy for cardiac sparing in patients with left-sided breast cancer. Front Oncol (2014) 4:257. doi:10.3389/fonc.2014.00257

5. Howe GR, Zablotska LB, Fix JJ, Egel J, Buchanan J. Analysis of the mortality experience amongst U. S. Nuclear Power Industry Workers after chronic low-dose exposure to ionizing radiation. Radiat Res (2004) 162:517-26. doi:10.1667/RR3258

6. Little MP, Tawn EJ, Tzoulaki I, Wakeford R, Hildebrandt G, Paris F, et al. Review and meta-analysis of epidemiological associations between low/ moderate doses of ionizing radiation and circulatory disease risks, and their possible mechanisms. Radiat Environ Biophys (2009) 49:139-53. doi:10.1007/ s00411-009-0250-Z

7. Little MP. A review of non-cancer effects, especially circulatory and ocular diseases. Radiat Environ Biophys (2013) 52:435-49. doi:10.1007/ s00411-013-0484-7.A

8. Schultz-Hector S, Trott K-R. Radiation-induced cardiovascular diseases: is the epidemiologic evidence compatible with the radiobiologic data? Int J Radiat Oncol Biol Phys (2007) 67:10-8. doi:10.1016/j.ijrobp.2006.08.071

9. Rader DJ, Daugherty A. Translating molecular discoveries into new therapies for atherosclerosis. Nature (2008) 451:904-13. doi:10.1038/nature06796

10. Hoel DG. Ionizing radiation and cardiovascular disease. Ann N Y Acad Sci (2006) 1076:309-17. doi:10.1196/annals.1371.001

11. Andreassi MG, Botto N. DNA damage as a new emerging risk factor in atherosclerosis. Trends Cardiovasc Med (2003) 13:270-5. doi:10.1016/ S1050-1738(03)00109-9

12. Di Lisa F, Kaludercic N, Carpi A, Menab R, Giorgio M. Mitochondria and vascular pathology. Pharmacol Rep (2009) 61:123-30. doi:10.1016/ S1734-1140(09)70014-3

13. Finsterer J. Is atherosclerosis a mitochondrial disorder? Vasa (2007) 36:229-40. doi:10.1024/0301-1526.36.4.229

14. Ito TK, Yokoyama M, Yoshida Y, Nojima A, Kassai H, Oishi K, et al. A crucial role for CDC42 in senescence-associated inflammation and atherosclerosis. PLoS One (2014) 9:e102186. doi:10.1371/journal.pone.0102186

15. Bert C, Engenhart-Cabillic R, Durante M. Particle therapy for noncancer diseases. Med Phys (2012) 39:1716-27. doi:10.1118/1.3691903

16. Tsujii H, Kamada T. A review of update clinical results of carbon ion radiotherapy. Jpn J Clin Oncol (2012) 42:670-85. doi:10.1093/jjco/hys104

17. Loeffler JS, Durante M. Charged particle therapy - optimization, challenges and future directions. Nat Rev Clin Oncol (2013) 10:411-24. doi:10.1038/ nrclinonc. 2013.79

18. Takahashi Y, Teshima T, Kawaguchi N, Hamada Y, Mori S, Madachi A, et al. Heavy ion irradiation inhibits in vitro angiogenesis even at sublethal dose. Cancer Res (2003) 63:4253-7.

19. Lanza V, Pretazzoli V, Olivieri G, Pascarella G, Panconesi A, Negri R. Transcriptional response of human umbilical vein endothelial cells to low doses of ionizing radiation. J Radiat Res (2005) 46:265-76. doi:10.1269/ jrr.46.265

20. Rombouts C, Aerts A, Beck M, De Vos WH, Van Oostveldt P, Benotmane MA, et al. Differential response to acute low dose radiation in primary and immortalized endothelial cells. Int J Radiat Biol (2013) 89:841-50. doi:10.310 9/09553002.2013.806831

21. Kraft G, Daues HW, Fischer B, Kopf U, Leibold H, Quis D, et al. Irradiation chamber and sample changes for biological samples. Nucl Instrum Methods (1980) 168:175-9. doi:10.1016/0029-554X(80)91249-5

22. Kraft-Weyrather W, Kraft G, Ritter S, Scholz M, Stanton J. The preparation of biological targets for heavy-ion experiments up to $20 \mathrm{MeV} / \mathrm{u}$. Nucl Instrum Methods Phys Res A (1989) 282:22-7. doi:10.1016/0168-9002(89)90104-6
23. Haberer T, Becher W, Schardt D, Kraft G. Magnetic scanning system for heavy ion therapy. Nucl Instrum Methods Phys Res A (1993) 330:296-305. doi:10.1016/0168-9002(93)91335-K

24. Franken NAP, Rodermond HM, Stap J, Haveman J, van Bree C. Clonogenic assay of cells in vitro. Nat Protoc (2006) 1:2315-9. doi:10.1038/nprot.2006.339

25. Fenech M. The in vitro micronucleus technique. Mutat Res (2000) 455:81-95. doi:10.1016/S0027-5107(00)00065-8

26. Meijer AE, Kronqvist U-SE, Lewensohn R, Harms-Ringdahl M. RBE for the induction of apoptosis in human peripheral lymphocytes exposed in vitro to high-LET radiation generated by accelerated nitrogen ions. Int J Radiat Biol (1998) 73:169-77. doi:10.1080/095530098142554

27. Johnson VL, Ko SCW, Holmstrom TH, Eriksson JE, Chow SC. Effector caspases are dispensable for the early nuclear morphological changes during chemical-induced apoptosis. J Cell Sci (2000) 113:2941-53.

28. Cosarizza A, Baccarani-Contri M, Kalashnikova G, Franceschi C. A new method for the cytofluorimetric analysis of mitochondrial membrane potential using the J-aggregate forming lipophilic cation 5,5,6,6'-tetrachloro-1,1'3,3'-tetraethylbenzimidazolcarbocyanine iodide (JC-1). Biochem Biophys Res Commun (1993) 197:40-5. doi:10.1006/bbrc.1993.2438

29. Cornforth M. Analyzing radiation-induced complex chromosome rearrangements by combinatorial painting. Radiat Prot Dosimetry (2001) 155:643-59.

30. Hooning MJ, Botma A, Aleman BMP, Baaijens MHA, Bartelink H, Klijn JGM, et al. Long-term risk of cardiovascular disease in 10-year survivors of breast cancer. J Natl Cancer Inst (2007) 99:365-75. doi:10.1093/jnci/djk064

31. Hendry JH, Akahoshi M, Wang LS, Lipshultz SE, Stewart FA, Trott KR. Radiation-induced cardiovascular injury. Radiat Environ Biophys (2008) 47:189-93. doi:10.1007/s00411-007-0155-7

32. Chen Y-H, Pan S-L, Wang J-C, Kuo S-H, Cheng JC-H, Teng C-M. Radiationinduced VEGF-C expression and endothelial cell proliferation in lung cancer. Strahlenther Onkol (2014) 190:1154-62. doi:10.1007/s00066-014-0708-z

33. Ebrahimian T, Le Gallic C, Stefani J, Dublineau I, Yentrapalli R, HarmsRingdahl S, et al. Chronic gamma-irradiation induces a dose-rate-dependent pro-inflammatory response and associated loss of function in human umbilical vein endothelial cells. Radiat Res (2015) 183:447-54. doi:10.1667/RR13732.1

34. Weyrather WK, Ritter S, Scholz M, Kraft G. RBE for carbon track-segment irradiation in cell lines of differing repair capacity. Int J Radiat Biol (1999) 75:1357-64. doi:10.1080/095530099139232

35. Habermehl D, Ilicic K, Dehne S, Rieken S, Orschiedt L, Brons S, et al. The relative biological effectiveness for carbon and oxygen ion beams using the raster-scanning technique in hepatocellular carcinoma cell lines. PLoS One (2014) 9:e113591. doi:10.1371/journal.pone.0113591

36. Hei TK, Marchese MJ, Hall EJ. Radiosensitivity and sublethal damage repair in human umbilical cord vein endothelial cells. Int J Radiat Oncol Biol Phys (1987) 13:879-84. doi:10.1016/0360-3016(87)90103-9

37. Manti L, Durante M, Elsaesser T, Gialanella G, Pugliese M, Ritter S, et al. Premature senescence in human endothelial cells exposed to carbon ions. GSI Sci Rep (2007) 1:350.

38. Raicu M, Vral A, Thierens H, De Ridder L. Radiation damage to endothelial cells in vitro, as judged by the micronucleus assay. Mutagenesis (1993) 8:335-9. doi:10.1093/mutage/8.4.335

39. Laurent C, Voisin P, Pouget J-P. DNA damage in cultured skin microvascular endothelial cells exposed to gamma rays and treated by the combination pentoxifylline and alpha-tocopherol. Int J Radiat Biol (2006) 82:309-21. doi:10.1080/09553000600733150

40. Morgan WF. Is there a common mechanism underlying genomic instability, bystander effects and other nontargeted effects of exposure to ionizing radiation? Oncogene (2003) 22:7094-9. doi:10.1038/sj.onc.1206992

41. Zahnreich S, Melnikova L, Winter M, Nasonova E, Durante M, Ritter S, et al. Radiation-induced premature senescence is associated with specific cytogenetic changes. Mutat Res (2010) 701:60-6. doi:10.1016/j.mrgentox.2010.03.010

42. Vavrova J, Rezacova M. The importance of senescence in ionizing radiation-induced tumour suppression. Folia Biol (Praha) (2011) 57:41-6.

43. Shah DJ, Sachs RK, Wilson DJ. Radiation-induced cancer: a modern view. $\mathrm{Br}$ J Radiol (2012) 85:1166-73. doi:10.1259/bjr/25026140

44. Yentrapalli R, Azimzadeh O, Sriharshan A, Malinowsky K, Merl J, Wojcik A, et al. The PI3K/Akt/mTOR pathway is implicated in the premature senescence of primary human endothelial cells exposed to chronic radiation. PLoS One (2013) 8:e70024. doi:10.1371/journal.pone.0070024 
45. Favero G, Paganelli C, Buffoli B, Rodella LF, Rezzani R. Endothelium and its alterations in cardiovascular diseases?: life style intervention. Biomed Res Int (2014) 2014:801896. doi:10.1155/2014/801896

46. Dimri GP, Leet X, Basile G, Acosta M, Scorrt G, Roskelley C, et al. A biomarker that identifies senescent human cells in culture and in aging skin in vivo. Proc Natl Acad Sci U S A (1995) 92:9363-7. doi:10.1073/pnas.92.20.9363

47. Grossi G, Bettega D, Calzolari P, Durante M, Elsässer T, Gialanella G, et al. Late cellular effects of 12 C ions. Nuovo Cim (2008) 31:39-47. doi:10.1393/ ncc/i2008-10278-4

48. Oh C, Bump EA, Kim J-S, Janigro D, Mayberg MR. Induction of a senescence-like phenotype in bovine aortic endothelial cells by ionizing radiation. Radiat Res (2001) 156:232-40. doi:10.1667/0033-7587(2001)156[023 2:IOASLP]2.0.CO;2

49. Igarashi K, Sakimoto I, Kataoka K, Ohta K, Miura M. Radiation-induced senescence-like phenotype in proliferating and plateau-phase vascular endothelial cells. Exp Cell Res (2007) 313:3326-36. doi:10.1016/j. yexcr.2007.06.001

50. Kim KS, Kim JE, Choi KJ, Bae S, Kim DH. Characterization of DNA damage-induced cellular senescence by ionizing radiation in endothelial cells. Int J Radiat Biol (2014) 90:71-80. doi:10.3109/09553002.2014.859763

51. Zhang L, Aviv H, Gardner JP, Okuda K, Patel S, Kimura M, et al. Loss of chromosome 13 in cultured human vascular endothelial cells. Exp Cell Res (2000) 260:357-64. doi:10.1006/excr.2000.4997

52. Wagner M, Hampel B, Bernhard D, Hala M, Zwerschke W, Jansen-Dürr P. Replicative senescence of human endothelial cells in vitro involves G1 arrest, polyploidization and senescence-associated apoptosis. Exp Gerontol (2001) 36:1327-47. doi:10.1016/S0531-5565(01)00105-X

53. Kim JH, Jenrow KA, Brown SL. Mechanisms of radiation-induced normal tissue toxicity and implications for future clinical trials. Radiat Oncol J (2014) 32:103-15. doi:10.3857/roj.2014.32.3.103

54. Davidson SM, Duchen MR. Endothelial mitochondria: contributing to vascular function and disease. Circ Res (2007) 100:1128-41. doi:10.1161/01. RES.0000261970.18328.1d

55. Donato AJ, Eskurza I, Silver AE, Levy AS, Pierce GL, Gates PE, et al. Direct evidence of endothelial oxidative stress with aging in humans: relation to impaired endothelium-dependent dilation and upregulation of nuclear factor-kappaB. Circ Res (2007) 100:1659-66. doi:10.1161/01.RES.0000269183.13937.e8

56. Barjaktarovic Z, Schmaltz D, Shyla A, Azimzadeh O, Schulz S, Haagen J, et al. Radiation-induced signaling results in mitochondrial impairment in mouse heart at 4 weeks after exposure to X-rays. PLoS One (2011) 6:e27811. doi:10.1371/journal.pone.0027811

57. Smiley ST, Reers M, Mottola-Hartshorn C, Lin M, Chen A, Smith TW, et al. Intracellular heterogeneity in mitochondrial membrane potentials revealed by a J-aggregate-forming lipophilic cation JC-1. Proc Natl Acad Sci U S A (1991) 88:3671-5. doi:10.1073/pnas.88.9.3671

58. Lyng FM, Seymour CB, Mothersill C. Production of a signal by irradiated cells which leads to a response in unirradiated cells characteristic of initiation of apoptosis. Br J Cancer (2000) 83:1223-30. doi:10.1054/bjoc.2000.1433

59. Wang W, Yang S, Su Y, Xiao Z, Wang C, Li X, et al. Enhanced antitumor effect of combined triptolide and ionizing radiation. Clin Cancer Res (2007) 13:4891-9. doi:10.1158/1078-0432.CCR-07-0416

60. Nair S, Nair RRK, Srinivas P, Srinivas G, Pillai MR. Radiosensitizing effects of plumbagin in cervical cancer cells is through modulation of apoptotic pathway. Mol Carcinog (2008) 47:22-33. doi:10.1002/mc

61. Samraj AK, Sohn D, Schulze-Osthoff K, Schmitz I. Loss of caspase-9 reveals its essential role for caspase- 2 activation and mitochondrial membrane depolarization. Mol Biol Cell (2007) 18:84-93. doi:10.1091/mbc.E06

62. Kimura M, Cao X, Patel S, Aviv A. Survival advantage of cultured human vascular endothelial cells that lost chromosome 13. Chromosoma (2004) 112:317-22. doi:10.1007/s00412-004-0276-6

63. Anno K, Hayashi A, Takahashi T, Mitsui Y, Ide T, Tahara H. Telomerase activation induces elongation of the telomeric single-stranded overhang, but does not prevent chromosome aberrations in human vascular endothelial cells. Biochem Biophys Res Commun (2007) 353:926-32. doi:10.1016/j. bbrc.2006.12.112

64. Giacinti C, Giordano A. RB and cell cycle progression. Oncogene (2006) 25:5220-7. doi:10.1038/sj.onc. 1209615

Conflict of Interest Statement: The authors declare that the research was conducted in the absence of any commercial or financial relationships that could be construed as a potential conflict of interest.

Copyright (C) 2016 Helm, Lee, Durante and Ritter. This is an open-access article distributed under the terms of the Creative Commons Attribution License (CC BY). The use, distribution or reproduction in other forums is permitted, provided the original author(s) or licensor are credited and that the original publication in this journal is cited, in accordance with accepted academic practice. No use, distribution or reproduction is permitted which does not comply with these terms. 